\title{
СИНТЕЗ ГРАФИТ-КОРУНДОВЫХ ОГНЕУПОРНЫХ КОМПОЗИЦИОННЫХ МАТЕРИАЛОВ МЕТОДОМ КОНТРОЛИРОВАННОГО ПИРОЛИЗА
}

\section{Бабаханова 3. А.}

\section{ВВЕДЕНИЕ}

В настоящее время огнеупорные материалы широко используются в химической, металлургической, машиностроительной, авиационной промышленности, космонавтике, нефтеперерабатывающей и других отраслях промышленности. В то же время уделяется особое внимание научным исследованиям по созданию наноструктурных новых составов и разработке новых технологий получения огнеупорных материалов, устойчивых к воздействию высоких температур, динамических сил, органических и неорганических растворителей, высокого давления.

Обзор в области технологий производства огнеупорных материалов и композитов показал, что научные исследования проводятся в ведущих научных центрах и высших образовательных учреждениях мира, в том числе в The Refractories Institute ${ }^{1}$ (США), University of Padova (Италия) ${ }^{2}$, University of Chemical Technology and Metallurgy (Болгария), Beijing University of Technology, Wuhan University of Science and Technology ${ }^{3}$, Xi' an University of Architecture and Technology (Китай), Graphite India Limited, Nippon Graphite

1 The Refractories Institute. URL: https://www.refractoriesinstitute.org/tripages/tri-whitepages.asp (дата обращения: 19.11.2020).

2 Dasan Arish, Elsayed Hamada, Kraxner Jozef, Galusek Dušan, Bernardo Enrico. Hierarchically Porous 3D-printed Akermanite Scaffolds from Silicones and Engineered Fillers. Journal of the European Ceramic Society. 2019. № 39. DOI: 10.1016/j.jeurceramsoc.2019.06.021.

3 Wang Heng, Li Yawei, Zhu Tianbin, Sang Shaobai, Wang Qinghu. Microstructures and mechanical properties of $\mathrm{Al}_{2} \mathrm{O}_{3}-\mathrm{C}$ refractories with addition of microcrystalline graphite. Ceramics International. 2014. № 40. P. 11139-11148. DOI: 10.1016/j.ceramint.2014.03.139. 
Industries Co. Ltd. ${ }^{4}$ (Индия), Seoul National University, Korea Polytechnic University (Корея), Riga Technical University, Institute of Silicate Materials (Латвия), Ural State Mining University, NITU MISiS, Российском химико-технологическом университете (Россия), Институте материаловедения «Физика-Солнце», Институте общей и неорганической химии $\mathrm{AH}$ РУз, Ташкентском химикотехнологическом институте (Узбекистан).

Техническая керамика - сравнительно новый вид материалов, и поэтому масштабы ее производства как по объему, так и по стоимости продукции существенно уступают производству традиционных металлических и полимерных материалов. Вместе с тем темпы роста ее выпуска (от 15 до $25 \%$ ежегодно) намного превышают соответствующие показатели для стали, алюминия и других металлов ${ }^{5}$.

Технические керамические компоненты находят все большее применение в самых различных отраслях, в частности, текущий ассортимент одной только европейской компании CeramTec включает более 10000 различных продуктов, компонентов и деталей технической керамики, а также широкий спектр высококачественных керамических материалов и собственных разработок компании ${ }^{6}$.

Особый класс технической керамики с высокими термическими характеристиками - огнеупоры. Огнеупоры способны выдерживать механические и физико-химические воздействия при высоких температурах, в связи с чем они широко применяются для кладки различных теплотехнических агрегатов. Наибольшее применение находят кремнеземистые, алюмосиликатные и магнезиальные огнеупоры.

Аналитический обзор специальной литературы показал, что разработке графитсодержащих огнеупорных материалов посвящено большое количество зарубежных исследований, однако в Узбекистане, несмотря на высокую потребность использования их в металлургической отрасли, отсутствуют работы в этом

${ }^{4}$ Raja B.V.R. Recent Developments in Secondary Steel Making Processes. IIM Metal News. 2007. Vol. 10. No. 1. February. P. 19-26.

${ }^{5}$ Матренин С.В., Слосман А.И. Техническая керамика. Томск : Изд-во ТПУ, 2004. $75 \mathrm{c}$.

6 Markets and Applications for CeramTec Products Are Nearly Everywhere.URL: https://www.ceramtec.com (дата обращения: 19.11.2020). 
направлении. В настоящее время производство огнеупорных керамических материалов налажено на нескольких предприятиях Республики Узбекистан: ТПП «Огнеупор» является основным производителем огнеупорной продукции, цеха по производству огнеупорных керамических материалов имеются на предприятиях «Узбекский комбинат тугоплавких и жаропрочных металлов», «Бекобод огнеупор», «Узбекский металлургический комбинат» и другие Основной продукцией являются шамотные и кислотоупорные изделия.

Разработка новых высокоэффективных составов является основным направлением развития мировой огнеупорной промышленности.

Использование огнеупоров с более длительным сроком службы приводит к снижению удельного расхода огнеупоров в расчете на тонну стали ${ }^{7}$ Северная Америка, Европа и Япония потребляют между 8 и 10 кг огнеупоров на тонну стали, в то время как в Китае около 23 кг/т стали. Эти высокие уровни потребления существенно снизятся в течение следующих пяти лет.

\section{1. Выбор составов и технологии получения огнеупорных композиционных материалов для металлургической отрасли}

В современных производствах металлургической отрасли при разливке жидких металлов и футеровке печей и агрегатов, работающих в условиях высоких температур, для защиты их не огнеупорных частей и внешней среды от действия тепловой энергии и агрессивных реагентов-расплавов, горячих газов и другого используются огнеупорные керамические изделия ${ }^{8}$. Использование в качестве огнеупоров керамических материалов объясняется удачным сочетанием различных свойств: огнеупорности, термостойкости, износостойкости, шлако- и кислотоустойчивости, теплопроводности и другого.

Для нужд металлургической, химической и других отраслей выпускаются тигли, ковши и другие огнеупорные изделия на основе

${ }^{7}$ China Continues to Dominate Refractories Despite a Slowing Steel Industry. URL: http://www.refractories-worldforum.com/global-news/729-steel-industry-andchina.html (дата обращения: 19.11.2020).

${ }^{8}$ Lee W.E., Zhang S., Karakus M. Refractories: Controlled microstructure composites for extreme environments. Journal of Materials Science. 2004. No. 39. P. 6675-6685. URL: https://doi.org/10.1023/B:JMSC.0000045599.84988.9e. 
таких материалов: оксида алюминия (корундовая, алундовая, высокоглиноземистая керамика); карбида кремния; периклаза; графита; графитосодержащих материалов ${ }^{9}$ графита с пироуглеродным покрытием; различных огнеупорных материалов (периклазовых, корундовых, корундо-периклазовых, муллитокорундовых, бадделеито-корундовых и тому подобных).

В частности, для футеровки наиболее изнашиваемых участков тепловых агрегатов черной и цветной металлургии А.М. Чуклаем и другими был предложен высокостойкий огнеупор шпинельнопериклазо-углеродистого состава ${ }^{10}$. В качестве основы огнеупора использован зернистый периклаз - 15-30 \%; мелкозернистой алюмомагниевой шпинели - 20-30 \%; дисперсной смеси периклаза с алюмомагниевой шпинелью - 4-18\%; углеродсодержащего материала - 4-8 \%; органического связующего - $1-5 \%$ комбинированного антиоксиданта на основе порошка алюминия и алюмомагниевого сплава и порошка карбида кремния. Полученные огнеупоры отличались повышенной шлакоустойчивостью по отношению к шлакам низкоосновного характера - скорость

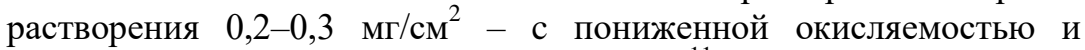
повышенным показателем термопрочности ${ }^{11}$. Однако предлагаемые составы содержат в качестве антиоксиданта активные металлы, работа с которыми в производственных условиях затруднительна в связи с их чрезвычайной химической активностью в кислородной среде. Также получение огнеупорного материала связано с предварительным синтезом и измельчением алюмосиликатной шпинели, что требует значительных дополнительных энергозатрат.

В работе В.П. Семянникова и других ${ }^{12}$ предложен углеродсодержащий огнеупор для футеровок плавильных и металлоперерабатывающих агрегатов с содержанием (в масс. \%):

${ }^{9}$ Matrix for high-performance ceramic matrix composite : Pat. No.US 2001/0008865 A1. Tetsuo Nakayasu, Yamaguchi-Ken (JP) ; заявл. 25.02.99 ; опубл. 19.07.01.

${ }^{10}$. Шпинельно-периклазо-углеродистый огнеупор : пат. 2167123 Российская Федерация : С04B35/035, С04В35/043, № 97118322/03 ; заявл. 30.10.97 ; опубл. 20.05.01. Бюл. № 14.

11 Кащеев И.Д., Земляной К.Г. Особенности структуры и свойств тонких порошков шпинели и периклаза после различных видов помола. Керамика $u$ композиционные материаль : тезисы докладов Всеросс.конф., г. Сыктывкар, 20-27 июня 2004 г. Сыктывкар, 2004. С. 184-185.

12 Углеродсодержащий огнеупор : пат. 20768849 Российская Федерация : С04B35/043, С04B35/443, № 9696113624 ; заявл. 22.07.96 ; опубл. 10.04.97. 
алюмомагниевой шпинели от 10 до 70, спеченного периклаза от 15 до 50, дисперсного периклаза от 10 до 25, графита от 5 до 15 и углеродистого связующего от 1 до 8 масс. \% (сверх 100 \%). Пустоты в материале заполнены углеродистой связкой, которая компенсирует объемные изменения при термоударах и препятствует проникновению внутрь огнеупора газов, металла и шлаков. Синтез материала требует значительных количеств предварительно синтезированной шпинели, что в производственных условиях приводит к излишним энергозатратам.

B работе W.S. Resende и других ${ }^{13}$ предложены огнеупорные графитсодержащие муллит-корундовые составы для чёрной и цветной металлургии. Коррозионная стойкость огнеупоров в системе $\mathrm{Al}_{2} \mathrm{O}_{3}-\mathrm{MgO}-\mathrm{C}$ была исследована на шлакоустойчивость при различных соотношениях $\mathrm{CaO} / \mathrm{SiO}_{2}$ в шлаке; установлено, что огнеупорность может быть увеличена путем увеличения коэффициента $\mathrm{Al}_{2} \mathrm{O}_{3} / \mathrm{C}$. Выбраны составы с соотношением компонентов $\mathrm{Al}_{2} \mathrm{O}_{3} / \mathrm{C}: 12,9 ; 13,6$ и 19,2 , в качестве связки использована фенольная смола. Наличие графита в составе массы обеспечивало тугоплавкость, высокую теплопроводность, низкие значения теплового расширения и низкую смачиваемость шлаком. При этом оптимальное содержание графита составляло 6 масс. \%, что достаточно высоко, чтобы дать хороший комбинированный эффект, и достаточно мало, чтобы не помешать диффузии ионов, ответственных за формирование муллита.

Минералогический состав полученных материалов представлен корундом, муллитом, периклазом и графитом. Наилучшие значения шлакоустойчивости показал состав с содержанием компонентов $\mathrm{Al}_{2} \mathrm{O}_{3} / \mathrm{C}=12,9$ с плотностью образцов 3,17 гр/см ${ }^{3}$ и кажущейся пористостью $4 \%$. Такой состав интересен для дальнейшего рассмотрения и изучения возможностей синтеза с другими типами связок.

Кроме классических методов получения новых типов технической керамики, в частности, огнеупоров и функциональной керамики, в настоящее время разрабатываются современные методы синтеза: золь-гель технологии, методы контролированного пиролиза с использованием прекерамических соединений,

${ }^{13}$ Resende W.S., Stoll R.M., Justus S.M., Andrade R.M. and oth. Key features of alumina/magnesia/graphite refractories for steel ladle lining. Journal of the European Ceramic Society. 2000. № 20. P. 1419-1427. DOI: 10.1016/S0955-2219(00)00004-2. 
химического и физического осаждения из газовой фазы и другие. В основном эти методы являются трудноуправляемыми (золь-гель технологии) или требуют специального дорогостоящего оборудования (химическое и физическое осаждение из газовой фазы), в связи с чем разработки находятся на стадии лабораторных и экспериментальных исследований.

Технология синтеза методом контролированного пиролиза с использованием активных наполнителей "Active-Filler-Controlled Pyrolysis" (AFCOP) была впервые предложена для получения функциональных керамических материалов и композитов в работе $\mathrm{Greil}^{14}$. Метод контролированного пиролиза позволяет получать объемные керамические компоненты на основе тугоплавких систем Si-Me-C-N-O (Me = Ti, Cr, V, Mo, Si, B, CrSi $2, \mathrm{MoSi}_{2}$ и др.) благодаря использованию прекерамических кремнийорганических полимеров, таких как поликарбосиланы, полисилазаны, полисилоксаны и другие ${ }^{15}$.

Применение силиконов (полисилоксанов, поликарбосилоксанов, поликарбосиланов, полисилазанов, полиборосилазанов, полиборосилоксанов) в технологии керамики позволяет с относительной легкостью синтезировать технические материалы со связями $\mathrm{Si}-\mathrm{N}-$ $\mathrm{Si}, \mathrm{Si}-\mathrm{C}-\mathrm{Si}, \mathrm{Si}-\mathrm{C}-\mathrm{N}-\mathrm{Si}$ (силаны, силоксаны, силазаны и другие), твердофазовый синтез которых требует высоких температур обработки (выше $\left.1600^{\circ} \mathrm{C}\right)^{16}$. Основное преимущество использования силиконов в синтезе технических материалов - это возможность контроля состава синтезируемого материала, простота и управляемость синтеза (в отличие от методов золь-гель синтеза), возможность использования всех видов формовки (литьевого, пластического, полусухого, сухого прессования, экструзии и

${ }^{14}$ Greil P. Active-filler-controlled pyrolysis of preceramic polymers. Journal of Amer. Ceram. Soc. 1995. № 78. P. 835-848. DOI: https://doi.org/10.1111/j.11512916.1995.tb08404.x.

${ }^{15}$ Fedorova A., Michelsen L., Scheffler M. Polymer-derived ceramic tapes with small and negative thermal expansion coefficients. Journal of the Europ. Ceram. Soc. 2017. 08.034. № 38. 2. P. 719-725. https://doi.org/10.1016/j.jeurceramsoc. 2017.08.034.

16 O'Masta M.R., Stonkevitch E., Porter K.A., Bui P.P., Eckel Z.C., Schaedler T.A. Additive manufacturing of polymer-derived ceramic matrix composites. Journal of Amer. Ceram. Soc. 2020. № 103. P. 6712-6723. URL: https://doi.org/10.1111/jace.17275. 
других). Благодаря этому силиконы имеют огромный потенциал для использования в качестве связки для керамических порошков.

При этом в методе контролированного пиролиза возможно использование как инертных, так и активных наполнителей. Инертные наполнители представляют собой керамические порошки, которые не реагируют с керамическим остатком силиконовой матрицы, газами разложения или окружающей атмосферы ${ }^{17}$.

Активные наполнители - металлические или интерметаллические порошки - реагируют во время пиролиза с газами разложения, образующимися при нагревании, или атмосферой в печи, с керамическим остатком из силиконовой матрицы ${ }^{18}$. Используемые металлические наполнители имеют размеры в диапазоне нескольких микрон из-за соображений безопасности, так как очень мелкие металлические частицы проявляют повышенную химическую активность и огнеопасны в использовании ${ }^{19}$.

Таким образом, обзор научной и патентной литературы показал, что для производства высокоогнеупорных керамических материалов является перспективным изучение составов на основе корунда, оксида магния, кремнезема и графита ${ }^{20}$; определенный интерес представляет разработка современных технологий синтеза технической керамики со специальными термическими и химическими свойствами методом контролированного пиролиза, что и выбрано целью нашего исследования.

При получении огнеупорных керамических композиционных материалов в качестве термореактивной кремнийорганической связки был использован фенилметил полисилоксан H44 SILRES ${ }^{\circledR}$. $\mathrm{Al}_{2} \mathrm{O}_{3}$ вводили через нанодисперсный порошок $\gamma$ - модификации

17 Steinau M. Travitzky N. Gegner J. Hofmann J. Greil P. Polymer-Derived ceramics for advanced bearing applications. Adv. Ceram. Mater. 2008. № 10. P. 1141-1146. DOI: 10.1002/adem.200800194.

${ }^{18}$ Kathy Lu, Donald Erb. Polymer derived silicon oxycarbide-based coatings. International Materials Reviews. 2018. № $63 \quad$ (3). $\begin{array}{llll}\text { P. } & 139 .\end{array}$ DOI: 10.1080/09506608.2017.1322247.

${ }^{19}$ Anggono J. Derby B. Intermediate phases in mullite synthesis via aluminumand alumina-filled polymethylsiloxane. Journal of Amer. Ceram. Soc. 2005. № 88. P. 2085-2091. DOI: 10.1111/j.1551-2916.2005.00416.x.

20 Chen Zhe, Yan Wen, Schafföner Stefan, Dai Yajie, Wang Qiang, Li Guangqiang. A novel approach to lightweight alumina-carbon refractories for flow control of molten steel. Journal of the Amer. Ceram. Soc. 2020. DOI: $10.1111 /$ jace. 17137 . 
$\mathrm{Al}_{2} \mathrm{O}_{3}$ (Puralox); $\mathrm{MgO}$ - через $\mathrm{Mg}(\mathrm{OH})_{2}$ (BITOSSI, Italy); графит вводился частично с силиконом Н44, частично путём добавления графитового концентрата. При этом были использованы коммерческий концентрат графита (Cometox Srl) и графитовый концентрат местного производства GK-2, полученный путём обогащения графитизированного сланца проявления Захчахона $(\text { Узбекистан })^{21}$.

К преимуществам использования кремнийорганических соединений при синтезе керамических материалов и композитов относится их возможность при нагревании более $350-1000^{\circ} \mathrm{C}$ образовывать структуру аморфной керамики со связями $\mathrm{Si}-X^{22}$. Кремнийорганические соединения (силиконы) имеют химическую формулу $\left[R_{n} \mathrm{Si} X(2-0,5 n)\right]_{m}$, где $R$ - это $\mathrm{H}, \mathrm{CH}_{3}$, винил, фенил и другие группы; $X$ - это O, N, C, Si и B ${ }^{23}$.

Технология получения кремнийорганических соединений является широкодоступной, а сами силиконы - недорогими, нетоксичными и распространенными материалами, находящими применение в самых различных областях производства техники ${ }^{24}$, бытовых продуктов, строительства и других ${ }^{25}$

\section{2. Получение графит-корундовой керамики методом управляемого пиролиза}

Нами была исследована возможность применения метода управляемого пиролиза для получения наноструктурных

${ }^{21}$ Babakhanova Z., Aripova M., Khodjaev N., Khamidov R. The Study of The Mineralogical Composition and Flotation Parameters of Quartz-Graphitized Schist. Chemistry \& Chemical Technology. Lviv, 2016. Vol. 10. No. 3. P. 343-348. DOI: $10.23939 /$ chcht10.03.343.

${ }^{22}$ Fiocco L., Babakhanova Z., Bernardo E. Facile obtainment of luminescent glassceramics by direct firing of a preceramic polymer and oxide fillers. Ceramics International. 2016. № 42. P. 6770-6774. URL: www.elsevier. com/locate/ceramint. DOI: 10.1016/j.ceramint.2016.01.052.

${ }^{23}$ Bernardo E., Fiocco L., Parcianello G., Storti E., Colombo P. Advanced ceramics from preceramic polymers modified at the nano-scale : A review. Materials. 2014. № 7. P. 1927-1956. DOI: 10.3390/ma7031927.

24 Бабаханова 3.А. Синтез композитов с люминесцентными свойствами на основе алюмосиликатов редкоземельных элементов с использованием кремнийорганических соединений. Композиционные материалы. 2018. № 4. С. 9-15.

${ }^{25}$ Griggio F., Bernardo E., Colombo P., Messing G.L. Kinetic studies of mullite synthesis from alumina nanoparticles and a preceramic polymer. Journal of the Amer. Ceram. Soc. 2008. № 91. P. 2529-2533. DOI: 10.1111/j.1551-2916.2008.02515.x. 
огнеупорных композиционных материалов и технической керамики с функциональными свойствами. Оптимальные составы графитсодержащих керамических материалов были синтезированы с использованием кремнийорганических связок - силиконов.

Химический состав графит-керамической массы, в масс. \% $\mathrm{SiO}_{2}-3,5 ; \mathrm{Al}_{2} \mathrm{O}_{3}-83 ; \mathrm{MgO}-7 ; \mathrm{C}-6,5$. Приготовлены 2 состава состав С-1 с использованием коммерческого концентрата графита, состав С-2 с использованием графитового концентрата проявления Захчахона.

При нагревании более $500{ }^{\circ} \mathrm{C}$ силиконы способны образовывать структуру аморфной керамики со связями $\mathrm{Si}-\mathrm{O}$. При этом разрушение связей $\mathrm{Si}-\mathrm{CH}_{3}$ приводит к образованию атомов кремния с ненасыщенными валентностями. При температуре $600-1200^{\circ} \mathrm{C}$ силикон $\mathrm{H} 44$ разлагается согласно реакции (1) с образованием 84 \% керамического остатка:

$$
\mathrm{Si}_{3} \mathrm{O}_{4,6} \mathrm{C}_{8,4} \rightarrow 2,3 \mathrm{SiO}_{2}+0,7 \mathrm{SiC}+7,75 \mathrm{C} \quad \text { (в среде } \mathrm{N}_{2} \text { ), }
$$

Получение графит-корундовых керамических изделий методом контролированного пиролиза с использованием активных наполнителей включало такие стадии ${ }^{26}$ :

-подготовку шихты, состоящей из смеси исходных компонентов. Предварительное растворение силикона $\mathrm{H} 44$ в изопропаноле осуществлялось из расчёта 0,6 гр силикона в 10 мл растворителя. Для получения однородной и стабильной композиции смеси выдерживались в ультразвуковой ванне в течение 15-20 мин. Приготовленные суспензии (керамический наполнитель + силикон + растворитель) высушивались при $40{ }^{\circ} \mathrm{C}$ в течении 5-10 ч., затем измельчались в агатовой ступке;

-изготовление образцов керамики (операции компактирования и обжига образцов) осуществлялось методом горячего прессования под давлением. Приготовленный порошок был отпрессован при $180^{\circ} \mathrm{C}$ под давлением $20 \mathrm{MPa}$ в виде таблеток диаметром 13 мм и толщиной 3-3,5 мм. Температура $180^{\circ} \mathrm{C}$ необходима для образования перекрестных связей в структуре полимера;

${ }^{26}$ Babakhanova Z., Aripova M., Bernardo E. The Synthesis Of Luminescent Glass-Ceramic Materials Activated With Europium Ions Using Silicon-Organic Compounds (Silicones). Glass and Ceramics. 2016. Vol. 73. No. 3-4. July. P. 124-127. DOI: 10.1007/s10717-016-9839-2. 
-обжиг образцов осуществляли при $1550{ }^{\circ} \mathrm{C}$ в течении 1 ч. в трубчатой печи в среде азота. Режим нагревания: $50-600^{\circ} \mathrm{C}-$ $10^{\circ} \mathrm{C} /$ мин.; 600-1550 ${ }^{\circ} \mathrm{C}-5^{\circ} \mathrm{C} /$ мин.; охлаждение образцов осуществляли со скоростью $10^{\circ} \mathrm{C} /$ мин (рис. 1).

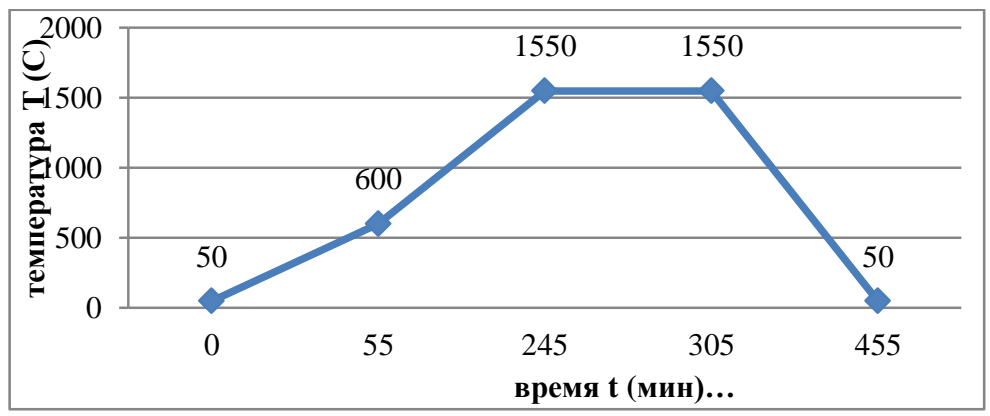

Рис. 1. Режим обжига графит-корундовых керамических материалов

\section{3. Изучение структуры, физико-механических свойств и шлакоустойчивости синтезированных материалов}

Для идентификации кристаллических фаз в синтезированных материалах использован дифрактометр Bruker AXS D8 Advance, Bruker, Germany. Условия съёмки $-\mathrm{Cu}-\mathrm{K}_{\alpha}-$ катод, шаг - 0,05, скорость съёмки 2 сек. Для расшифровки рентгенограмм использована программа Match! program package (Crystal Impact GbR, Bonn, Germany). Строение и структура материалов изучалась с использованием сканирующего электронного микроскопа (Carl Zeiss, Германия) с энерго-дисперсионным элементным анализатором.

Обжиг в среде азота. Минералогический состав синтезированных при $1550^{\circ} \mathrm{C}$ в среде азота материалов, установленный с помощью рентгенофазового анализа ${ }^{27}$, в масс. \%, приведен на рис. 2. В составе С-1 кристаллические фазы представлены оксинитридом алюминия $\mathrm{Al}_{2.85} \mathrm{O}_{3.45} \mathrm{~N}_{0.55}$ - 52, корундом - 45, графитом - 3. Состав С-2 представлен $\mathrm{Al}_{2.85} \mathrm{O}_{3.45} \mathrm{~N}_{0.55}$ - 34, корундом - 60, графитом - 6. Из-за низкого количества $\mathrm{Si}$ и $\mathrm{Mg}$ не

27 Бабаханова 3.А., Арипова М.Х. Синтез технических керамических материалов на основе кремнийорганических соединений. Узб. хим. журн. 2015. № 3. С. 16-21. 
образуют кристаллических форм. Присутствие оксинитрида алюминия $\mathrm{Al}_{2.85} \mathrm{O}_{3.45} \mathrm{~N}_{0.55}$ (№ 00-080-2171 в МАТСН!) со структурой типа кубической шпинели с параметрами решетки а $=0,795$ нм, $\mathrm{V}=0,502 \mathrm{Hм}^{3}$ в синтезированной высокоглиноземистой керамике улучшает механические и термические свойства материалов.

Необходимо отметить, что оксинитрид алюминия с общей формулой $(\mathrm{AlN})_{\mathrm{x}} \cdot\left(\mathrm{Al}_{2} \mathrm{O}_{3}\right)_{1-\mathrm{x}}$ является уникальным соединением, обладающим повышенными механическими и термическими свойствами. При относительно малом удельном весе $\mathrm{AlON}$ является в 4 раза прочнее закаленного стекла, современные технологии производства позволяют получать на его основе прозрачную керамику, в частности, в США налажен промышленный выпуск $\mathrm{AlON}$ стекол для применения в броневой технике ${ }^{28}$.

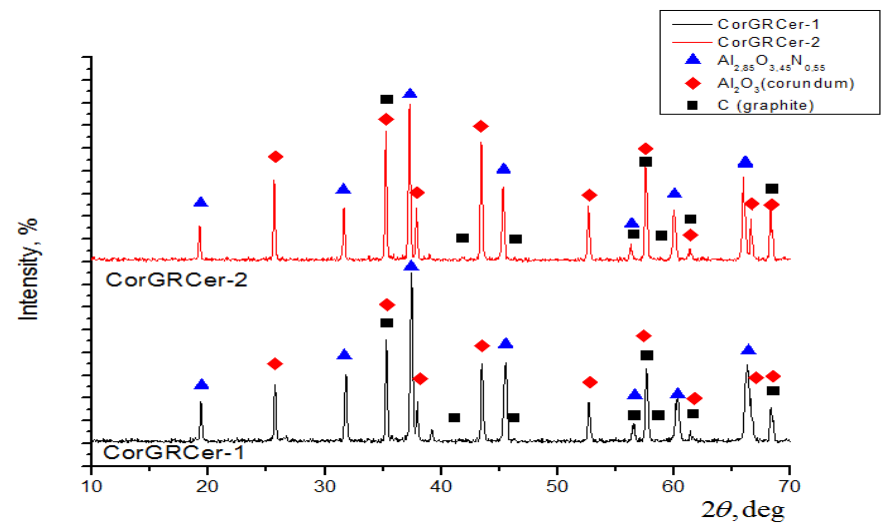

Рис. 2. Рентгенограммы синтезированных при $1550^{\circ} \mathrm{C}$ в среде азота графит-корундовых материалов состава С-1 и C-2

Однако широкому использованию $\mathrm{AlON}$ препятствует дороговизна его изготовления, так кака синтез требует высоких температур - $1950-1990^{\circ} \mathrm{C}$, давления и специфического термического оборудования.

В связи с этим в настоящее время актуальными являются разработки по энергосберегающим технологиям синтеза AlON для

28 ALON®Optical ceramics. URL: http://www.surmet.com/technology/ alon-optical-ceramics/index.php (дата обращения: 19.11.2020). 
обеспечения более высокого выхода ${ }^{29}$, а также снижения себестоимости конечного продукта ${ }^{30}$. К примеру, для получения однородных чистых порошков AlON Yingying Wang et al (2018 год) прокалили смесь $\gamma-\mathrm{Al}_{2} \mathrm{O}_{3} / \mathrm{C}$ с 5,8 масс.\% углерода в течение 2 часов при $1750^{\circ} \mathrm{C}$. Для уменьшения размера частиц методами сублимационной сушки, ультразвукового диспергирования использовалась шаровая мельница с жидким азотом ${ }^{31}$. Также в последнее время большой интерес вызывает оксинитрид алюминия как многообещающий люминофор для WLED и $\mathrm{FED}^{32}$. Изучение фазообразования в атмосфере азота при более высоких температурах для получения чистой кристаллической фазы $\mathrm{AlON}$ является предметом будущих исследований.

Обжсиг в окислительной среде (на воздухе). Обжиг керамики состава C-1 на воздухе осуществляли в диапазоне от 1000 до $1400{ }^{\circ} \mathrm{C}$. Результаты рентгенографического анализа для образца С-1, обожженного при различных температурах, приведены на рис. 3.

Минералогический состав синтезированных материалов приведен в таблице 1. Изучение процессов фазообразования при получении графит-корундовой керамики на воздухе показало, что при температурах $1000-1200^{\circ} \mathrm{C}$ в присутствии активной формы аморфного кремнезёма (продукт пиролиза силикона $\mathrm{H} 44$ ) происходит образование ряда силикатов магния и алюминия: кианита $\mathrm{Al}_{2} \mathrm{SiO}_{5}$, клиноэнстатита $\mathrm{MgSiO}_{3}$, пиропа $\mathrm{Mg}_{3} \mathrm{Al}_{2}\left(\mathrm{SiO}_{4}\right)_{3}$. При температурах выше $1250-1300{ }^{\circ} \mathrm{C}$ клиноэнстатит и пироп не обнаруживаются в продуктах синтеза. Также наблюдается полное

29 Способ получения шихты оксинитрида алюминия : пат. 2171793 Российская Федерация : С04B35/581, С01B21/072 ; заявл. 14.10.99 ; опубл. 10.08.01.

${ }^{30}$ Галахов А.В., Зеленский В.А., Коваленко Л.В., Забелин С.Ф., Алымов М.И. Жидкофазный синтез оксинитрида алюминия. Ученые записки Забайкальского государственного университета. $2013.2 \mathrm{https} / /$ cyberleninka.ru/ article/n/zhidkofaznyy-sintez-oksinitrida-alyuminiya.

31 Wang Yingying, Li Qinggang, Huang Shifeng, Cheng Xin, Hou Pengkun, Wang Yongchen, Chen Guanliang, Yi Shanling. Preparation and properties of AlON powders. Ceramics International. 2018. Vol: 44. Issue: 1. P. 471-476. DOI: 10.1016/j.ceramint.2017.09.200.

32 Ding Jianyan, Wei Yan, Liu Weiqing, Li Yanyan, Wu Quansheng, Zhou Jiangcong. Highly efficient and thermally stable narrow-band cyan-emitting aluminum oxynitride phosphor for WLEDs and FEDs. Chemical Engineering Journal. Vol. 403. 1 January 2021. 126382 (in press). URL: https://doi.org/10.1016/j.cej.2020.126382. 
связывание периклаза в составе шпинели с формированием стехиметрической структуры $\mathrm{MgAl}_{2} \mathrm{O}_{4}$.

$\mathrm{Al}_{2} \mathrm{SiO}_{5}$ имеет несколько полиморфных модификаций, при низких температурах обжига керамики он присутствует в виде кианита (триклинная сингония), при температуре выше $1350^{\circ} \mathrm{C}-$ в виде силлиманита (орторомбическая сингония). Несмотря на близость параметров кристаллической решетки (для кианита $\mathrm{a}=0,714 \mathrm{нм}, \mathrm{b}=0,787 \mathrm{нм}, \mathrm{c}=0,560$ нм; для силлиманита $\mathrm{a}=0,750 \mathrm{нм}$, $\mathrm{b}=0,774 \mathrm{Hм}, \quad \mathrm{c}=0,580$ нм), превращения между этими модификациями затруднительны вследствие того, что при переходе из одной структуры в другую происходит разрыв связей $\mathrm{Si}-\mathrm{O}, \mathrm{Al}-\mathrm{O}$ и приводит к реконструктивной перестройке структуры.

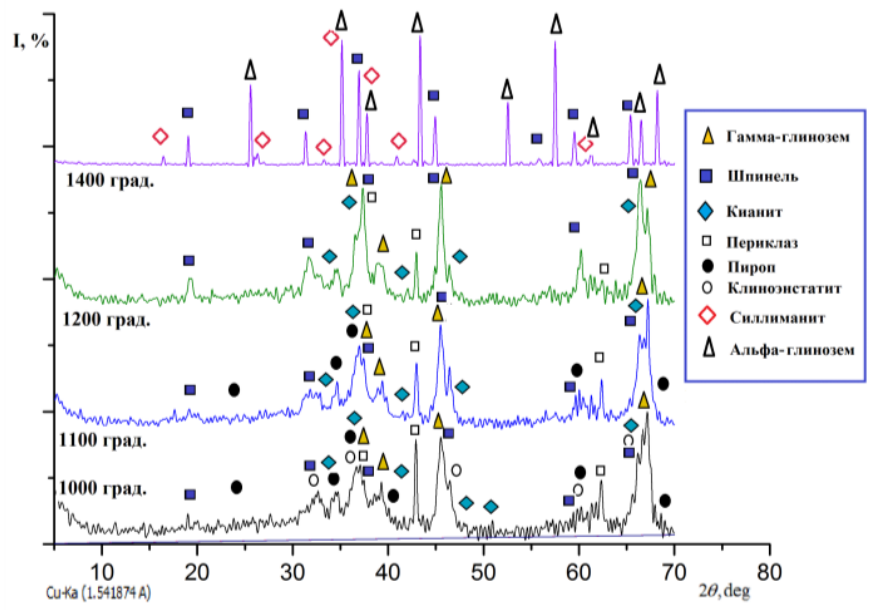

\section{Рис. 3. Рентгенограммы образца C-1, обжиг на воздухе при $1000-1400^{\circ} \mathrm{C}$}

Глинозем также имеет несколько модификаций, в частности, при низкотемпературном обжиге $\left(1000-1200^{\circ} \mathrm{C}\right)$ он присутствует в продуктах обжига в виде $\gamma$-глинозёма (кубическая сингония), при $1400^{\circ} \mathrm{C}$ - в виде $\alpha$-глинозёма корунда (ромбоэдрическая сингония). Превращение гамма-модификации в альфа-форму сопровождается уменьшением объема на 14,8 \%, что может привести к нежелательной усадке изделий. При этом плотность синтезированных керамик зависит от воздействия двух факторов: усадки при спекании корунда и расширения, которым сопровождается процесс шпинелеобразования. 
Образование новых шпинельных фаз приводит к частичной компенсации усадки изделий. Также, согласно И.Д. Кащееву (2017 год), использование $\gamma$-глинозёма позволяет снизить температуру

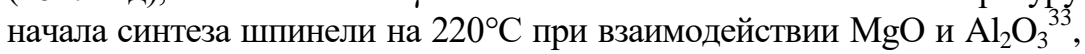
так как взаимодействие $\gamma$-глинозёма с $\mathrm{MgO}$ начинается при $700^{\circ} \mathrm{C}$, в то время как $\alpha$-глинозёма - при $920^{\circ} \mathrm{C}$. В связи с этим для более полного синтеза шпинели при пониженной температуре обжига был использован $\gamma$-глинозём.

Таблица 1

Минералогический состав обожженных на воздухе при 1000-1400 ${ }^{\circ} \mathrm{C}$ керамических образцов состава $\mathrm{C}-1$

\begin{tabular}{|c|c|c|c|c|}
\hline \multirow{2}{*}{$\begin{array}{c}\text { Кристаллическая } \\
\text { фаза (№ эталона в } \\
\text { программе Match!) }\end{array}$} & \multicolumn{4}{|c|}{$\begin{array}{c}\text { Содержание кристаллической фазы } \\
\text { в материале, масс. \% }\end{array}$} \\
\hline & $\begin{array}{l}\text { Обжиг } \\
\text { при } \\
1000^{\circ} \mathrm{C} \\
\end{array}$ & $\begin{array}{l}\text { Обжиг } \\
\text { при } \\
1100^{\circ} \mathrm{C}\end{array}$ & $\begin{array}{l}\text { Обжиг } \\
\text { при } \\
1200^{\circ} \mathrm{C} \\
\end{array}$ & $\begin{array}{c}\text { Обжиг } \\
\text { при } \\
1400^{\circ} \mathrm{C}\end{array}$ \\
\hline $\begin{array}{c}\alpha-\text {-глинозём } \\
\text { (корунд) } \\
\text { (№ 00-075-1862) }\end{array}$ & - & - & - & 66,9 \\
\hline $\begin{array}{c}\text { Шпинель } \mathrm{MgAl}_{2} \mathrm{O}_{4} \\
\text { (№ 00-073-1959) } \\
\end{array}$ & - & - & - & 27,7 \\
\hline $\begin{array}{c}\text { Твердый раствор со } \\
\text { структурой } \\
\text { шпинели } \\
\left(\mathrm{Mg}_{0,4} \mathrm{Al}_{0,6}\right) \mathrm{Al}_{1,8} \mathrm{O}_{4} \\
(№ 00-087-0340) \\
\end{array}$ & 3,8 & 8,8 & 14,8 & - \\
\hline $\begin{array}{c}\text { Периклаз Mgo } \\
\text { (№ 00-075-1525) } \\
\end{array}$ & 7,4 & 4,7 & 4,2 & - \\
\hline $\begin{array}{c}\text { Клиноэнстатит } \\
\mathrm{MgSiO}_{3} \\
\text { (№ 00-085-2494) }\end{array}$ & 12,4 & 16,4 & 8,4 & - \\
\hline $\begin{array}{c}\text { Пироп } \\
\mathrm{Mg}_{3} \mathrm{Al}_{2}\left(\mathrm{SiO}_{4}\right)_{3} \\
(№ \text { 00-076-0851) }\end{array}$ & 6,5 & 5,8 & - & - \\
\hline $\begin{array}{l}\text { Кианит } \mathrm{Al}_{2} \mathrm{SiO}_{5} \\
\text { (№ 00-083-1569) }\end{array}$ & 11,7 & 11,9 & 15,2 & - \\
\hline $\begin{array}{c}\text { Силлиманит } \\
\mathrm{Al}_{2} \mathrm{SiO}_{5} \\
\text { (№ 00-083-1566) } \\
\end{array}$ & - & - & - & 5,4 \\
\hline $\begin{array}{c}\gamma \text {-глинозём } \\
\text { (№ 00-074-2206) }\end{array}$ & 58,2 & 52,4 & 57,4 & - \\
\hline
\end{tabular}

${ }_{33}$ Кащеев И.Д., Земляной К.Г. Производство шпинели. Новые огнеупоры. Москва, 2017. № 3. С. 127-133. 
Образующийся при разложении гидроксида магния $\mathrm{MgO}$ активно взаимодействует с $\gamma$-глинозёмом с образованием твёрдого раствора со структурой шпинели $\left(\mathrm{Mg}_{0,4} \mathrm{Al}_{0,6}\right) \mathrm{Al}_{1,8} \mathrm{O}_{4}$ кубической сингонии с параметрами решётки $\mathrm{a}=0,798$ нм. В связи с избыточным содержанием в массах $\mathrm{Al}_{2} \mathrm{O}_{3}$ и его хорошей растворимостью в шпинели происходит образование твердого раствора с избыточным содержанием $\mathrm{Al}_{2} \mathrm{O}_{3}$. В твердом растворе состава $\left(\mathrm{Mg}_{0,4} \mathrm{Al}_{0,6}\right) \mathrm{Al}_{1,8} \mathrm{O}_{4}$ ионы алюминия (III) располагаются не только в октаэдрической позиции, но и в тетраэдрической.

Количество твёрдого раствора со структурой шпинели закономерно возрастает с ростом температуры обжига: 1000-1100$1200^{\circ} \mathrm{C}$ соответственно $3,8-8,8-14,8$ масс. \%. В составах, обожженных при $1400^{\circ} \mathrm{C}$, наблюдается формирование кубической шпинели $\mathrm{MgAl}_{2} \mathrm{O}_{4}$ с параметрами решётки $\mathrm{a}=0,805$ нм в количестве 27,7 масс. $\%$.

Таким образом, для получения огнеупорных материалов методом пиролиза при обжиге на воздухе оптимальная температура обжига составляет $1400^{\circ} \mathrm{C}$. При этом основными кристаллическими фазами керамики состава С-1 являются корунд $\alpha-\mathrm{Al}_{2} \mathrm{O}_{3}-66,9 \%$ и шпинель $\mathrm{MgAl}_{2} \mathrm{O}_{4}-27,7$ \%, с небольшим содержанием силлиманита $\mathrm{Al}_{2} \mathrm{SiO}_{5}-5,4 \%$.

Сравнения минералогического состава керамики С-1, синтезированной методом пиролиза силиконов и сравнительных составов № 76-77, полученных на основе сырьевых материалов электрокорунда (Казогнеупор), талько-магнезита Зинельбулакского месторождения (Узбекистан) и графитового концентрата Захчахона $(\text { Узбекистан })^{34}$, показали, что наличие небольших количеств оксидов-плавней во втором случае аналогично низкотемпературному обжигу в первом случае способствует образованию твёрдых растворов со структурой шпинели. В отсутствии примесей структурообразование в системе при температурах выше $1350^{\circ} \mathrm{C}$ сопровождается образованием шпинели и силлиманита.

Физико-механические свойства синтезированных в среде азота материалов приведены в таблице 2.

${ }^{34}$ Babakhanova Z., Aripova, M. Highly Refractory Alumina-Periclase-Carbon Ceramic Materials Based on a Spinel Binder. Refractories and Industrial Ceramics. 2019. № 59. DOI: 10.1007/s11148-019-00253-w. 
Таблица 2

Физико-механические свойства графит-корундовых материалов

\begin{tabular}{|c|c|c|c|c|}
\hline $\begin{array}{c}\text { Номер } \\
\text { образца }\end{array}$ & $\begin{array}{c}\text { Кажущаяся } \\
\text { пористость, } \\
\text { \% }\end{array}$ & $\begin{array}{c}\text { Водопоглоще } \\
\text { ние, \% }\end{array}$ & $\begin{array}{c}\text { Кажущийся } \\
\text { удельный } \\
\text { вес }\end{array}$ & $\begin{array}{c}\text { Объёмная } \\
\text { плотность, } \\
\text { кг/м }\end{array}$ \\
\hline C-1 & 39,017 & 17,779 & 3,599 & 2195 \\
\hline C-2 & 27,374 & 10,489 & 3,593 & 2610 \\
\hline
\end{tabular}

Синтезированные керамические материалы имеют относительно высокие показатели кажущейся пористости и водопоглощения, однако это не влияет отрицательно на шлакоустойчивость образцов в связи с их высокой огнеупорностью и отсутствием жидкой фазы даже при очень высоких температурах $\left(1800^{\circ} \mathrm{C}\right)$.

Размеры кристаллов в графит-корундовой керамике оптимального состава C-2 при обжиге в среде азота определены на основе СЭМ-анализа (рис. 4) и составляют: для корунда - 0,6-0,8 мк; для оксинитрида алюминия - 100-200 нм. Это свидетельствует о формировании в материале наноструктурной матрицы.

Оптимальные результаты установлены для состава С-2, полученного на основе обогащенного графитового концентрата проявления Захчахона (Узбекистан), кремнийорганической связки H44 и наноразмерного наполнителя - оксида алюминия.

Изучение минералогического состава и устойчивости синтезированного материала С-2 по отношению к металлургическому шлаку Алмалыкского горно-металлургического комбината (Узбекистан) осуществлялось статическим методом при $1550^{\circ} \mathrm{C}$ в течении 2 ч, образцы после воздействия шлака изучались с помощью электронно-микроскопического анализа, результаты которого приведены на рис. 5. На рис. 5 четко видна граница разделения фаз керамического материала (слева) и фазы, богатой железом (справа), а также глубина проникновения металлургического шлака. 


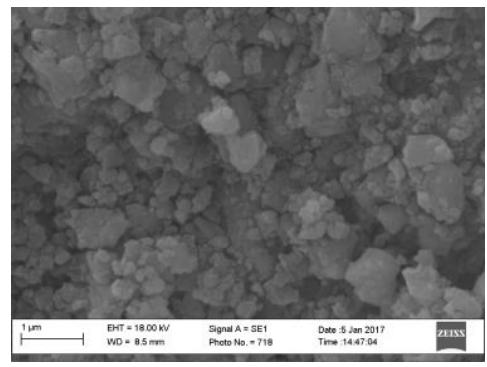

A

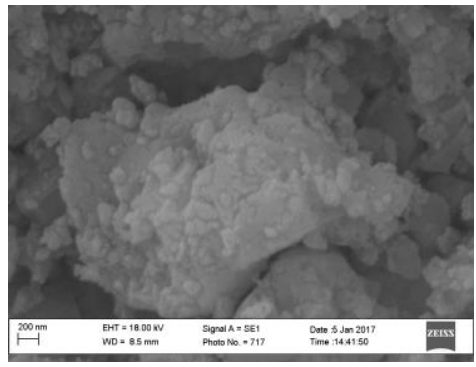

Б

Рис. 4. Электронно-микроскопические снимки графит-корундовой керамики оптимального состава CGC-2 (обжиг в среде азота)

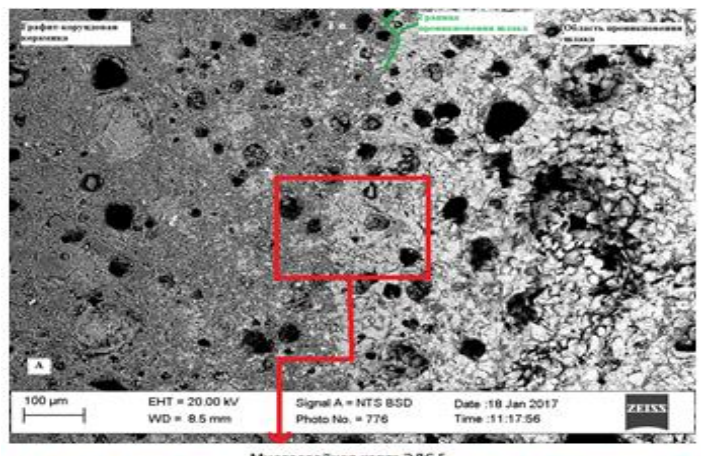

Mrsorochop̉enaа kapra 3 ACS

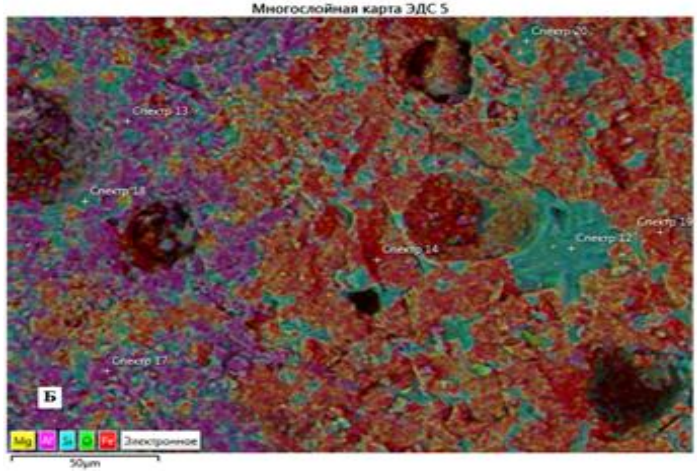

А - общий вид, Б - кристаллы оксинитрида алюминия (В-спектр 2)

Рис. 5. Электронно-микроскопические снимки оптимального состава С-2 (А) и распределение элементов на срезе образца (Б) после проверки на шлакоустойчивость 
Результаты спектрального анализа показали, что образец слева представлен минералами корунда (спектр 13 и 17) и силлиманита (спектр 18). Область проникновения шлака (на рис. 6 - справа) представлена кристаллами силлиманита (спектр 12,20) и железосодержащей фазой с включениями корунда (спектр 14,19).
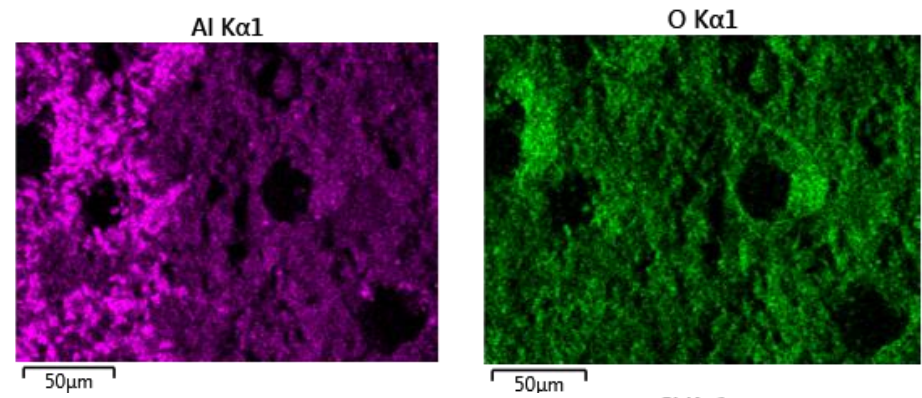

Fe Ka1
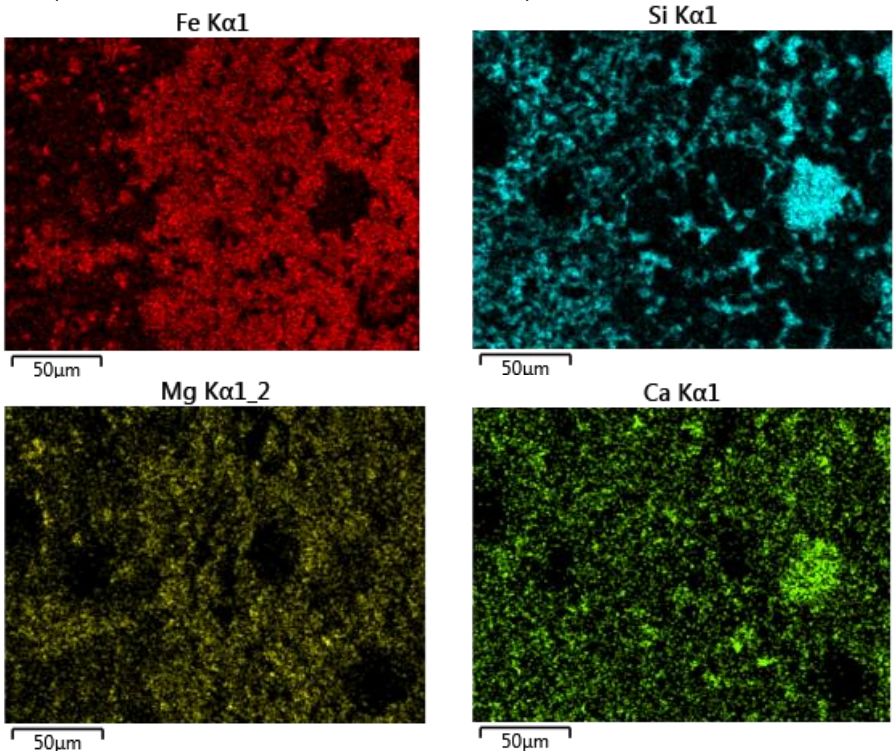

Рис. 6. Распределение элементов в графит-корундовом керамическом образце CGC-2, подвергнутом воздействию металлургического шлака АГМК

Визуальное наблюдение показало, что шлак растекся по поверхности образца, микроскопическим анализом была 
установлена глубина проникновения шлака внутрь образца на $0,1-0,06$ мм (в 10 раз меньше, чем у графитшамотных огнеупоров). Изучение картины распределения $\mathrm{Fe}$ (рис. 6) показывает путь проникновения шлака по порам внутри образца. Механические свойства образца С-2 определялись методом неразрушающего динамического резонанса на 5 образцах, прочность на изгиб варьировалась от 60,95 до 75,12 МПа, модуль Юнга составлял от 88,7 до 106,6 ГПа.

Разработанная технологическая схема получения графиткорундовой керамики методом направленного пиролиза с использованием в качестве термореактивной связки силиконов приведена на рисунке 7.

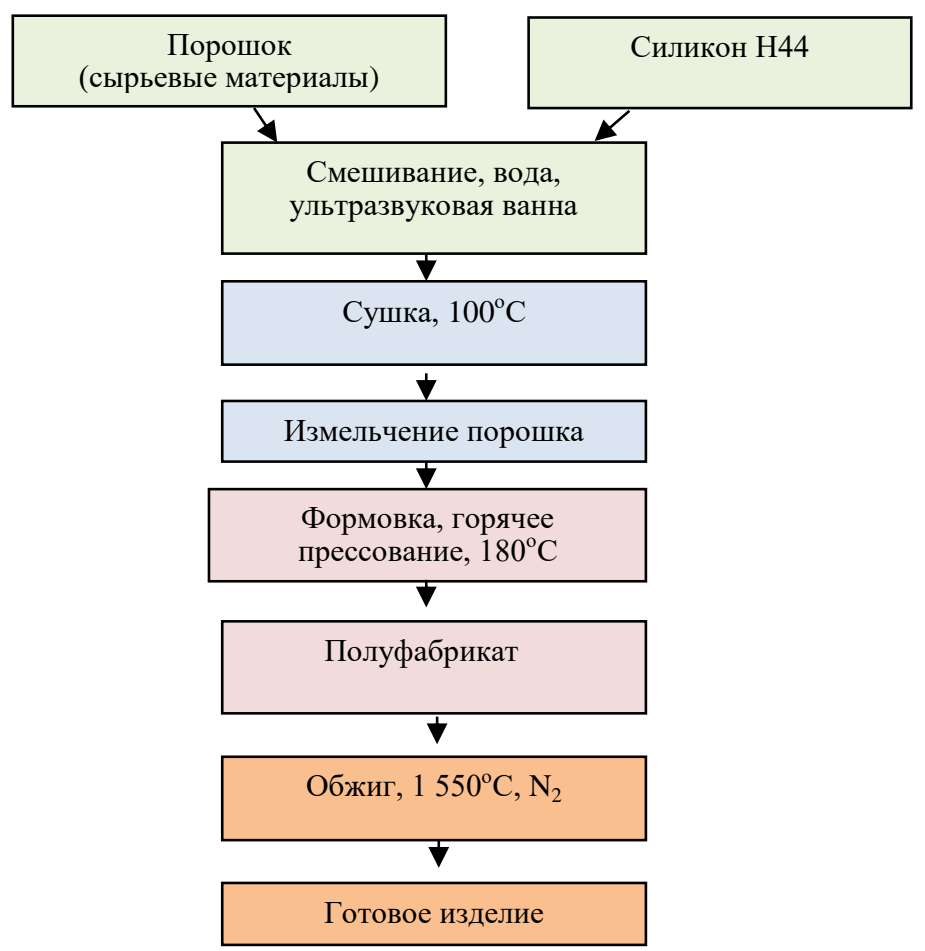

Рис. 7. Упрощенная технологическая схема получения графит-корундовой керамики 
По заключению предприятия «Огнеупор» (город Ташкент), синтезированные материалы относятся к высокоогнеупорным и характеризуются температурой плавления более $1800^{\circ} \mathrm{C}$; температурой начала деформации под нагрузкой $(0,02 \mathrm{\kappa H} / \mathrm{cm})-$ более $1700^{\circ} \mathrm{C}$; термостойкостью - 10 теплосмен и пористостью $22 \%$. Полученный графит-корундовый материал с содержанием шпинели отличается повышенной шлакоустойчивостью и механической прочностью, может быть рекомендован для использования в ответственных частях металлургического производства.

\section{ВЫВОДЫ}

Методом контролированного пиролиза (АFCOР) получены графитсодержащие шпинельнокорундовые керамические материалы, установлена зависимость состав - свойство для синтезированных материалов, высокоогнеупорные и шлакоустойчивые материалы с огнеупорностью более $1800^{\circ} \mathrm{C}$ рекомендованы для использования в наиболее ответственных переделах металлургической, химической и машиностроительной отраслей производства.

Установлено влияние среды на процессы фазообразования шпинель-корундовых керамических масс при направленном пиролизе с использованием кремнийорганических соединений и определено образование наряду с корундом в нейтральной среде оксинитридов алюминия переменного состава $(\mathrm{AlN})_{\mathrm{x}}\left(\mathrm{Al}_{2} \mathrm{O}_{3}\right)_{1-\mathrm{x}}$, в окислительной среде шпинели $\mathrm{MgAl}_{2} \mathrm{O}_{4}$ и силлиманита $\mathrm{Al}_{2} \mathrm{SiO}_{5}$, обеспечивающих их высокие термические свойства.

\section{АННОТАЦИЯ}

Исследована возможность получения методом контролированного пиролиза графитсодержащих шпинельнокорундовых керамических материалов, установлена зависимость состав - свойство для синтезированных материалов. При направленном пиролизе с использованием кремнийорганических соединений наряду с корундом кристаллическая фаза огнеупорных материалов представлена в нейтральной среде - оксинитридом алюминия переменного состава $(\mathrm{AlN})_{\mathrm{x}} \cdot\left(\mathrm{Al}_{2} \mathrm{O}_{3}\right)_{1-\mathrm{x}}$, в окислительной среде шпинелью $\mathrm{MgAl}_{2} \mathrm{O}_{4}$ и силлиманитом $\mathrm{Al}_{2} \mathrm{SiO}_{5}$, обеспечивающих их высокие термические свойства. 


\section{ЛИТЕРАТУРА}

1. The Refractories Institute. URL: https://www.refractoriesinstitute.org/ tri-pages/tri-whitepages.asp (дата обращения: 19.11.2020).

2. Dasan Arish, Elsayed Hamada, Kraxner Jozef, Galusek Dušan, Bernardo Enrico. Hierarchically Porous 3D-printed Akermanite Scaffolds from Silicones and Engineered Fillers. Journal of the European Ceramic Society. 2019. № 39. DOI: 10.1016/j.jeurceramsoc.2019.06.021.

3. Wang Heng, Li Yawei, Zhu Tianbin, Sang Shaobai, Wang Qinghu. Microstructures and mechanical properties of $\mathrm{Al}_{2} \mathrm{O}_{3}-\mathrm{C}$ refractories with addition of microcrystalline graphite. Ceramics International. $2014 . \quad$ № $40 . \quad$ P. $11139-11148$. DOI: 10.1016/j.ceramint.2014.03.139.

4. Raja B.V.R. Recent Developments in Secondary Steel Making Processes. IIM Metal News. 2007. Vol. 10. No. 1. February. P. 19-26.

5. Матренин С.В., Слосман А.И. Техническая керамика. Томск : Изд-во ТПУ, 2004. 75 с.

6. Markets and Applications for CeramTec Products Are Nearly Everywhere.URL: https://www.ceramtec.com (дата обращения: 19.11.2020).

7. China Continues to Dominate Refractories Despite a Slowing Steel Industry. URL: http://www.refractories-worldforum.com/globalnews/729-steel-industry-and-china.html (дата обращения: 19.11.2020).

8. Lee W.E., Zhang S., Karakus M. Refractories: Controlled microstructure composites for extreme environments. Journal of Materials Science. 2004. No. 39. P. 6675-6685. URL: https://doi.org/10.1023/B:JMSC.0000045599.84988.9e.

9. Matrix for high-performance ceramic matrix composite : Pat. No.US 2001/0008865 A1. Tetsuo Nakayasu, Yamaguchi-Ken (JP) ; заявл. 25.02.99 ; опубл. 19.07.01.

10.Шпинельно-периклазо-углеродистый огнеупор : пат. 2167123 Российская Федерация : С04B35/035, С04B35/043, № 97118322/03 ; заявл. 30.10.97 ; опубл. 20.05.01. Бюл. № 14.

11.Кащеев И.Д., Земляной К.Г. Особенности структуры и свойств тонких порошков шпинели и периклаза после различных видов помола. Керамика и композищионные материалы : тезисы докладов Всеросс.конф., г. Сыктывкар, 20-27 июня 2004 г. Сыктывкар, 2004. С. 184-185. 
12.Углеродсодержащий огнеупор : пат. 20768849 Российская Федерация : С04B35/043, С04В35/443, № 9696113624 ; заявл. 22.07.96 ; опубл. 10.04.97.

13. Resende W.S., Stoll R.M., Justus S.M., Andrade R.M. and oth. Key features of alumina/magnesia/graphite refractories for steel ladle lining. Journal of the European Ceramic Society. 2000. № 20. P. 1419-1427. DOI: 10.1016/S0955-2219(00)00004-2.

14. Greil P. Active-filler-controlled pyrolysis of preceramic polymers. Journal of Amer. Ceram. Soc. 1995. № 78. P. 835-848. DOI: https://doi.org/10.1111/j.1151-2916.1995.tb08404.x.

15. Fedorova A., Michelsen L., Scheffler M. Polymer-derived ceramic tapes with small and negative thermal expansion coefficients. Journal of the Europ. Ceram. Soc. 2017. 08.034. № 38. 2. P. 719-725. https://doi.org/10.1016/j.jeurceramsoc.2017.08.034.

16. O’Masta M.R., Stonkevitch E., Porter K.A., Bui P.P., Eckel Z.C., Schaedler T.A. Additive manufacturing of polymer-derived ceramic matrix composites. Journal of Amer. Ceram. Soc. 2020. № 103. P. 6712-6723. URL: https://doi.org/10.1111/jace.17275.

17. Steinau M. Travitzky N. Gegner J. Hofmann J. Greil P. PolymerDerived ceramics for advanced bearing applications. Adv. Ceram. Mater. 2008. № 10. P. 1141-1146. DOI: 10.1002/adem.200800194.

18. Kathy Lu, Donald Erb. Polymer derived silicon oxycarbide-based coatings. International Materials Reviews. 2018. № 63 (3). P. 139. DOI: 10.1080/09506608.2017.1322247.

19. Anggono J. Derby B. Intermediate phases in mullite synthesis via aluminum- and alumina-filled polymethylsiloxane. Journal of Amer. Ceram. Soc. 2005. № 88. P. 2085-2091. DOI: 10.1111/j.15512916.2005.00416.x.

20. Chen Zhe, Yan Wen, Schafföner Stefan, Dai Yajie, Wang Qiang, Li Guangqiang. A novel approach to lightweight alumina-carbon refractories for flow control of molten steel. Journal of the Amer. Ceram. Soc. 2020. DOI: 10.1111/jace.17137.

21. Babakhanova Z., Aripova M., Khodjaev N., Khamidov R. The Study of The Mineralogical Composition and Flotation Parameters of Quartz-Graphitized Schist. Chemistry \& Chemical Technology. Lviv, 2016. Vol. 10. No. 3. P. 343-348. DOI: 10.23939/chcht10.03.343.

22. Bernardo E., Fiocco L., Parcianello G., Storti E., Colombo P. Advanced ceramics from preceramic polymers modified at the nanoscale : A review. Materials. 2014. № 7. P. 1927-1956. DOI: $10.3390 / \mathrm{ma} 7031927$. 
23. Fiocco L., Babakhanova Z., Bernardo E. Facile obtainment of luminescent glass-ceramics by direct firing of a preceramic polymer and oxide fillers. Ceramics International. 2016. № 42. P. 6770-6774. URL: www.elsevier. com/locate/ceramint. DOI: 10.1016/j.ceramint.2016.01.052.

24.Бабаханова 3.А. Синтез композитов с люминесцентными свойствами на основе алюмосиликатов редкоземельных элементов с использованием кремнийорганических соединений. Композииионные материаль. 2018. № 4. С. 9-15.

25.Griggio F., Bernardo E., Colombo P., Messing G.L. Kinetic studies of mullite synthesis from alumina nanoparticles and a preceramic polymer. Journal of the Amer. Ceram. Soc. 2008. № 91. P. 2529-2533. DOI: 10.1111/j.1551-2916.2008.02515.x.

26. Babakhanova Z., Aripova M., Bernardo E. The Synthesis Of Luminescent Glass-Ceramic Materials Activated With Europium Ions Using Silicon-Organic Compounds (Silicones). Glass and Ceramics. 2016. Vol. 73. No. 3-4. July. P. 124-127. DOI: 10.1007/s10717-016-9839-2.

27.Бабаханова 3.А., Арипова М.Х. Синтез технических керамических материалов на основе кремнийорганических соединений. Узб. хим. журн. 2015. № 3. С. 16-21.

28.ALON®Optical ceramics. URL: http://www.surmet.com/ technology/alon-optical-ceramics/index.php (дата обращения: 19.11.2020).

29.Способ получения шихты оксинитрида алюминия : пат. 2171793 Российская Федерация : С04B35/581, С01B21/072 ; заявл. 14.10.99 ; опубл. 10.08.01.

30. Галахов А.В., Зеленский В.А., Коваленко Л.В., Забелин С.Ф., Алымов М.И. Жидкофазный синтез оксинитрида алюминия. Ученые записки Забайкальского государственного университета. 2013. https://cyberleninka.ru/article/n/zhidkofaznyy-sintez-oksinitrida-alyuminiya.

31.Wang Yingying, Li Qinggang, Huang Shifeng, Cheng Xin, Hou Pengkun, Wang Yongchen, Chen Guanliang, Yi Shanling. Preparation and properties of AlON powders. Ceramics International. 2018. Vol: 44. Issue: 1. P. 471-476. DOI: 10.1016/j.ceramint.2017.09.200.

32.Ding Jianyan, Wei Yan, Liu Weiqing, Li Yanyan, Wu Quansheng, Zhou Jiangcong. Highly efficient and thermally stable narrow-band cyan-emitting aluminum oxynitride phosphor for WLEDs and FEDs. Chemical Engineering Journal. Vol. 403. 1 January 2021. 126382 (in press). URL: https://doi.org/10.1016/j.cej.2020.126382. 
33. Кащеев И.Д., Земляной К.Г. Производство шпинели. Новые огнеупоры. Москва, 2017. № 3. С. 127-133.

34. Babakhanova Z., Aripova, M. Highly Refractory AluminaPericlase-Carbon Ceramic Materials Based on a Spinel Binder. Refractories and Industrial Ceramics. 2019. № 59. DOI: 10.1007/s11148-019-00253-w.

\section{Information about author:} Babakhanova Z. A., DSc in Technical Sciences, Associate Professor at the Department of Technology of Silicate Materilas and Rare Noble Metals Tashkent Chemical-Technological Institute 32, Navoi str., Tashkent, 100011, Uzbekistan 